\title{
SECULAR AND NONPOLAR VARIATION OF \\ WASHINGTON LATITUDE
}

\author{
DENNIS D. McCARTHY \\ University of Virgina, Charlottesville, Virginia, U.S.A.
}

\begin{abstract}
Observations of astronomical latitude made at Washington are analyzed for a secular trend. Comparison with the variation of latitude based on the path of the rotational pole of the International Polar Motion Service shows linear trends in good agreement. No evidence is found for a $24 \mathrm{yr}$ libration of the pole. Systematic differences between observed and derived latitudes indicate that there are nonpolar variations in Washington latitude. Evidence is presented for the correlation of seismic activity with abrupt changes in the nonpolar variation, and the consequences of a changing geopotential surface are discussed with regard to observations of the rotational pole of the Earth.
\end{abstract}

\section{Introduction}

Continuous observations of astronomical latitude have been made at the U.S. Naval Observatory in Washington, D.C., since October 1915 using a photographic zenith tube (PZT). Recently these observations were reduced again using a consistent method of reduction and an improved catalog of star positions and proper motions (McCarthy, 1970). This catalog was developed by minimizing the internal errors of the actual observations and applying statistical corrections to place the catalog on the FK4 system. The resultant series of values for the latitude of Washington is then a very consistent set of data useful for the examination of the trend in latitude over the past $55 \mathrm{yr}$.

The series of latitude observations made at Washington can be examined to determine the nature of the motion of the mean pole along the longitude of Washington independently from the data of the International Polar Motion Service.

\section{Observed Secular Variation}

From the series of Washington latitudes provided by the U.S. Naval Observatory, six year running means were calculated. These means are listed in Table I. The mean error of such a determination varies between 0.003 and 0 ".008. A general northward movement of the station is shown by these data. The method of least squares was used to determine a linear fit to these data. It shows that the latitude of Washington can be represented by the expression,

$$
\begin{gathered}
\phi=38^{\circ} 55^{\prime} 17^{\prime \prime} .401+00^{\prime \prime} .00301 \mathrm{yr}^{-1}(t-1950.0) \\
\pm 0^{\prime \prime} .005 \pm 0.00032
\end{gathered}
$$

The running means along with the linear fit are shown in Figure 1. 
TABLE I

Six year running means of Washington latitude

\begin{tabular}{|c|c|c|c|}
\hline Year & Mean $\phi$ & Year & Mean $\phi$ \\
\hline $\begin{array}{l}1919 \\
1920\end{array}$ & $\begin{array}{l}17 " 322 \\
17^{\prime \prime} 322\end{array}$ & & \\
\hline $\begin{array}{l}1921 \\
1922 \\
1923 \\
1924 \\
1925\end{array}$ & $\begin{array}{l}17^{\prime \prime} 332 \\
17^{\prime \prime} 333 \\
17^{\prime \prime 3} 32 \\
17^{\prime \prime 3} 327 \\
17^{\prime \prime} 331\end{array}$ & $\begin{array}{l}1946 \\
1947 \\
1948 \\
1949 \\
1950\end{array}$ & $\begin{array}{l}17 " .357 \\
17 " .349 \\
17 " 363 \\
17 " 349 \\
17 " 354\end{array}$ \\
\hline $\begin{array}{l}1926 \\
1927 \\
1928 \\
1929 \\
1930\end{array}$ & $\begin{array}{l}17 " .328 \\
17 " 3332 \\
17 " 337 \\
17 " 341 \\
17^{\prime \prime} 346\end{array}$ & $\begin{array}{l}1951 \\
1952 \\
1953 \\
1954 \\
1955\end{array}$ & $\begin{array}{l}17 " .355 \\
17 " .392 \\
17 " .407 \\
17 " 438 \\
17 " .480\end{array}$ \\
\hline $\begin{array}{l}1931 \\
1932 \\
1933 \\
1934 \\
1935\end{array}$ & $\begin{array}{l}17^{\prime \prime} 343 \\
17^{\prime \prime} 347 \\
17^{\prime \prime} 335 \\
17^{\prime \prime} 332 \\
17^{\prime \prime} 333\end{array}$ & $\begin{array}{l}1956 \\
1957 \\
1958 \\
1959 \\
1960\end{array}$ & $\begin{array}{l}17 " .500 \\
17 " .483 \\
17 " .501 \\
17 " .500 \\
17 " .478\end{array}$ \\
\hline $\begin{array}{l}1936 \\
1937 \\
1938 \\
1939 \\
1940\end{array}$ & $\begin{array}{l}17 " 331 \\
17 " 348 \\
17^{\prime \prime} 355 \\
17 " 370 \\
17 " 381\end{array}$ & $\begin{array}{l}1961 \\
1962 \\
1963 \\
1964 \\
1965\end{array}$ & $\begin{array}{l}17 " .450 \\
17 " .432 \\
17 " .421 \\
17 " .407 \\
17 " .411\end{array}$ \\
\hline $\begin{array}{l}1941 \\
1942 \\
1943 \\
1944 \\
1945\end{array}$ & $\begin{array}{l}17 " 390 \\
17 " 375 \\
17 " 368 \\
17 " 364 \\
17 " 361\end{array}$ & $\begin{array}{l}1966 \\
1967\end{array}$ & $\begin{array}{l}17 " .416 \\
17 " .418\end{array}$ \\
\hline
\end{tabular}

\section{Derived Secular Variation}

The International Polar Motion Service has listed the coordinates of the rotational pole in a left-handed system centered on the Conventional International Origin where the ' $x$ ' axis lies along $0^{\circ}$ longitude and the ' $y$ ' axis along $90^{\circ} \mathrm{W}$ longitude. Recently a complete list of the coordinates of the rotational pole was made available for the years 1899-1968 (Vicente and Yumi, 1969).

Running six year means of the polar coordinates were formed and these were converted to the derived latitude variations at Washington. The mean errors of these values were determined to vary between 0.003 and 0.014 . The results are listed in Table II. Again the method of least squares was employed to find a linear secular trend of $\left(0.00311 \pm 0\right.$ ".00025) $\mathrm{yr}^{-1}$ which is in good agreement with the value derived from Washington observations. The derived latitude variations along with the linear fit are shown in Figure 2. 


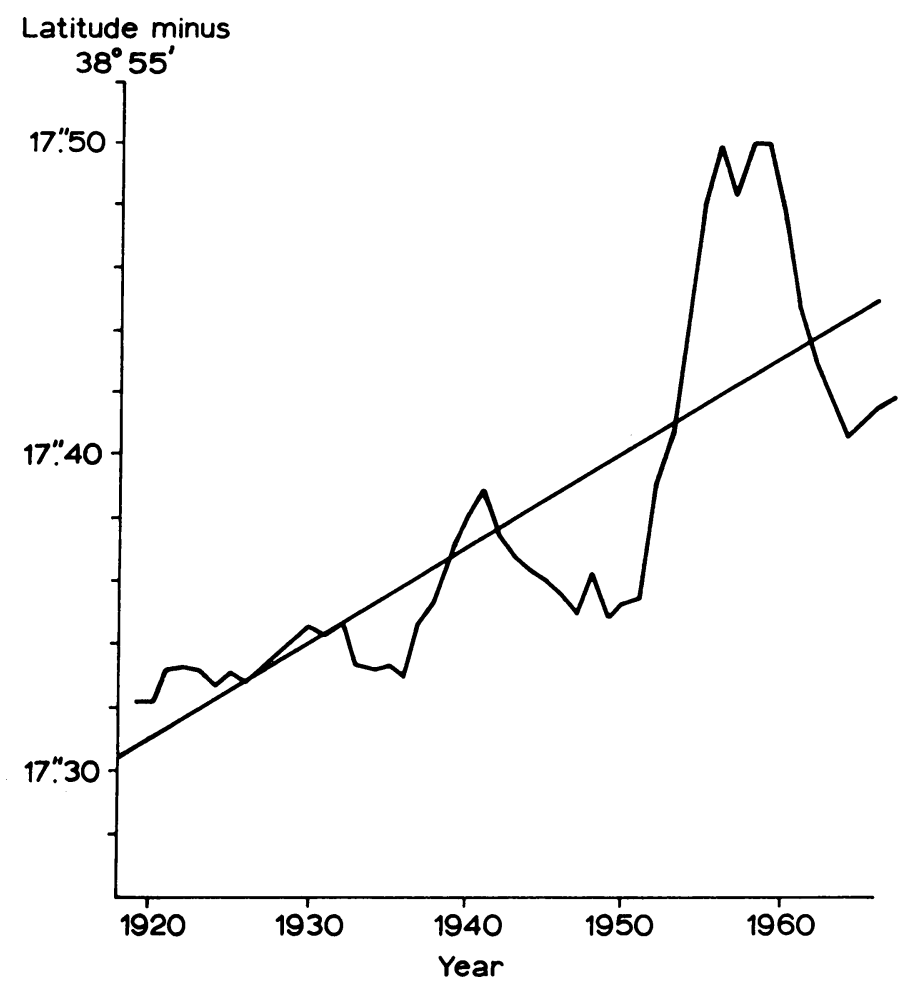

Fig. 1. Observed variation of Washington latitude.

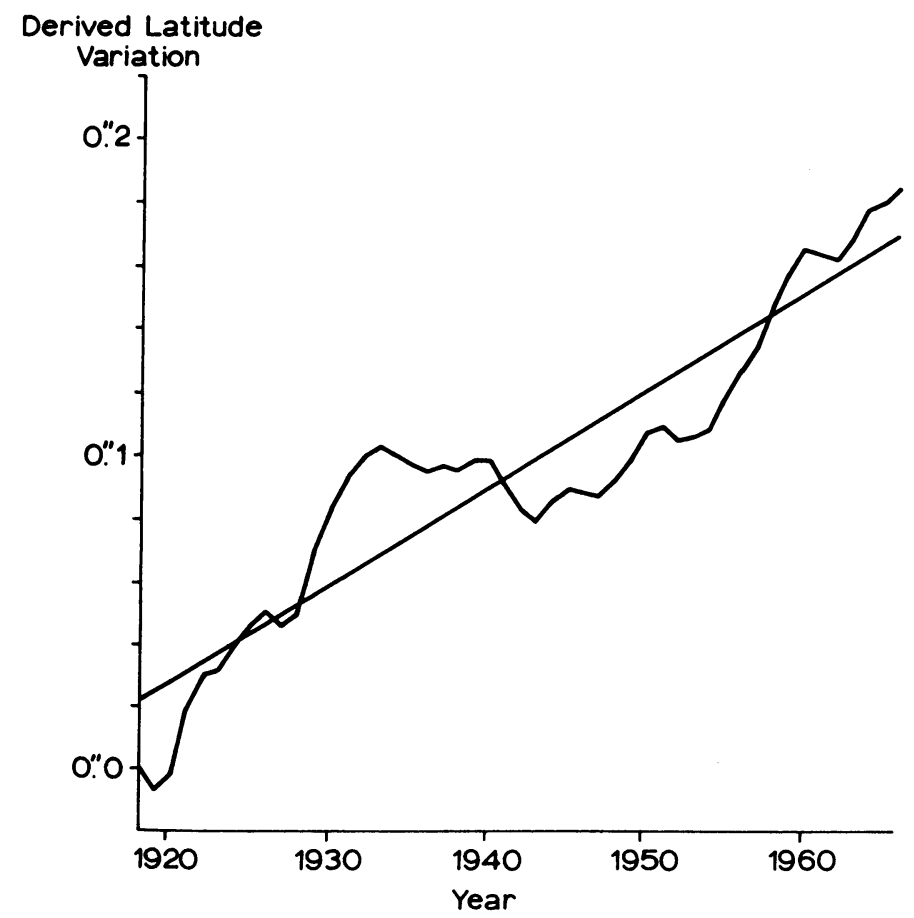

Fig. 2. Variation of Washington latitude derived from the IPMS pole position. 
TABLE II

Running six year means of derived IMPS variations

(normalized to zero in 1918)

\begin{tabular}{|c|c|c|c|}
\hline Year & Mean $\phi$ & Year & Mean $\phi$ \\
\hline $\begin{array}{l}1918 \\
1919 \\
1920\end{array}$ & $\begin{array}{r}0.000 \\
-0.007 \\
-0.002\end{array}$ & & \\
\hline $\begin{array}{l}1921 \\
1922 \\
1923 \\
1924 \\
1925\end{array}$ & $\begin{array}{l}0 ! 018 \\
0 ! 030 \\
0 ! 032 \\
0 ! 039 \\
0 ! 046\end{array}$ & $\begin{array}{l}1946 \\
1947 \\
1948 \\
1949 \\
1950\end{array}$ & $\begin{array}{l}0 ! 089 \\
0 ! 088 \\
0 ! 092 \\
0 ! 099 \\
0 ! 108\end{array}$ \\
\hline $\begin{array}{l}1926 \\
1927 \\
1928 \\
1929 \\
1930\end{array}$ & $\begin{array}{l}0 ! 051 \\
0 ! 046 \\
0 ! 050 \\
0 ! 070 \\
0 ! 084\end{array}$ & $\begin{array}{l}1951 \\
1952 \\
1953 \\
1954 \\
1955\end{array}$ & $\begin{array}{l}0 ! 110 \\
0 ! 106 \\
0 ! 107 \\
0 ! 109 \\
0 ! 120\end{array}$ \\
\hline $\begin{array}{l}1931 \\
1932 \\
1933 \\
1934 \\
1935\end{array}$ & $\begin{array}{l}0 ! 094 \\
0 ! 100 \\
0 ! 103 \\
0 ! 101 \\
0 ! 098\end{array}$ & $\begin{array}{l}1956 \\
1957 \\
1958 \\
1959 \\
1960\end{array}$ & $\begin{array}{l}0 ! 129 \\
0 ! 136 \\
0 ! 149 \\
0 ! 159 \\
0 ! 167\end{array}$ \\
\hline $\begin{array}{l}1936 \\
1937 \\
1938 \\
1939 \\
1940\end{array}$ & $\begin{array}{l}0 ! 096 \\
0 ! 097 \\
0 ! 096 \\
0 ! 099 \\
0 ! 099\end{array}$ & $\begin{array}{l}1961 \\
1962 \\
1963 \\
1964 \\
1965\end{array}$ & $\begin{array}{l}0 ! 165 \\
0 ! 163 \\
0 ! 170 \\
0 ! 179 \\
0 ! 181\end{array}$ \\
\hline $\begin{array}{l}1941 \\
1942 \\
1943 \\
1944 \\
1945\end{array}$ & $\begin{array}{l}0 ! 093 \\
0 ! 084 \\
0 ! 080 \\
0 ! 086 \\
0 ! 090\end{array}$ & 1966 & $0 ! 186$ \\
\hline
\end{tabular}

\section{Motion of the Mean Pole}

Despite the fact that completely different methods and star catalogs are used, the values of the linear trend as determined by Washington observations and that shown by the IPMS stations are the same. There can be little doubt that this linear rate represents a real secular change in latitude. However, the large, apparently systematic deviations shown in Figures 1 and 2 cast some doubt on the reality of a linear motion. The deviations from a straight line are plotted in Figure 3 and 4 for the Washington data and those of the IPMS. The effect of the proposed $24 \mathrm{yr}$ libration based on analytical expressions given by Markowitz (1960) is also shown on both plots. No evidence for such a motion is seen in the observations of Washington latitude, and inspection of the IPMS data seems to indicate that if libration does exist, motion of a longer period would seem to be more appropriate. 


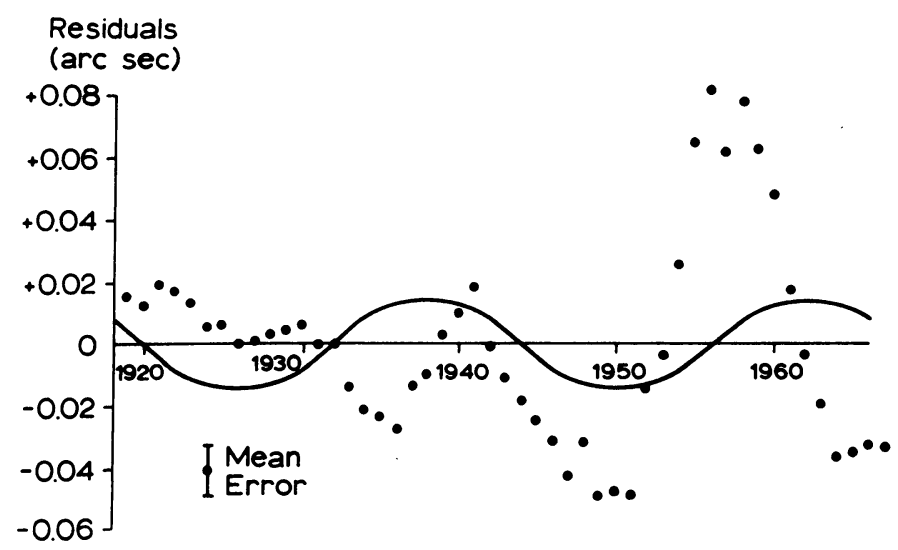

Fig. 3. Residuals from linear fit of Washington observed latitude. The solid line is the latitude variation along the meridian of Washington based on analytical expressions given by Markowitz (1960).

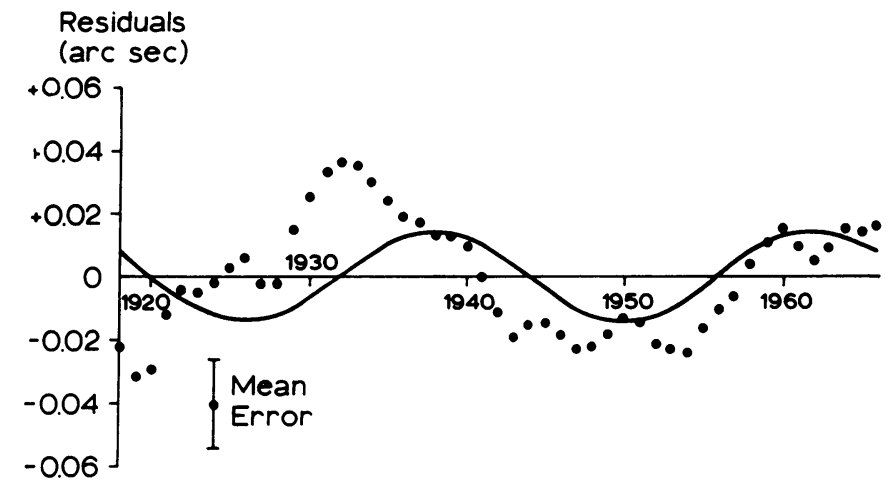

Fig. 4. Residuals from a linear fit of the latitude variation derived from the path of the rotational pole of the IPMS. The solid line is the latitude variation along the meridian of Washington based on analytical expressions given by Markowitz (1960).

TABLE III

Rates of Washington nonpolar latitude variation

\begin{tabular}{lcc}
\hline Interval & $\begin{array}{l}\text { Slope } \\
\text { (arc sec/yr) }\end{array}$ & $\begin{array}{l}\text { Mean Error } \\
\text { (arc sec/yr) }\end{array}$ \\
\hline $1919-1934$ & +0.00624 & \pm 0.00040 \\
$1934-1941$ & -0.00966 & \pm 0.00022 \\
$1941-1951$ & +0.00525 & \pm 0.00012 \\
$1951-1956$ & -0.02517 & \pm 0.00146 \\
$1956-1964$ & +0.01803 & \pm 0.00114 \\
$1964-1966$ & -0.00100 & -
\end{tabular}


It is not possible to establish the existence of a long period librational effect with any certainty using this relatively short series of observations. A much longer series is necessary to determine the reality of any such periodic librations.

\section{Comparison of Washington and IPMS Data}

The observations of Washington latitude and the latitudes derived from the IPMS pole positions are compared in Figure 5. The IPMS data are superimposed on the observational results by forcing the linear fit through the 1950.0 latitude shown by Equation (1). The difference between the two sets of data is shown in Figure 6. This shows systematic differences which appear to be much larger than can be attributed to observational errors. Although the reality of any periodic motion cannot be ascertained, the data can be fitted with a series of straight lines, the slopes of which are shown in Table III. These slopes change direction around the years 1934, 1941, 1951, 1956 , and 1964. If there is a physical mechanism causing this motion, it must be related to these abrupt changes in direction.

The magnitudes of the slopes and the frequency of the changes in direction appear to rule out systematic errors in the results of the IPMS or in the Washington observations. Since virtually the same catalog and reduction procedure has been used for all of the Washington data, one would not expect such linear trends to be due to systematic effects in the Washington observations. During its operation the IPMS made changes in star catalogs, reduction methods and coordinate systems. However, corrections have been applied by the IPMS in these data to make them consistent. The most important changes in the procedure of the IPMS which could produce such linear trends are the changes in the catalog of star positions and proper motions made in 1923, 1935, and 1955. The changes in 1935 and 1955 may be related to the observed changes in the direction of motion in 1934 and 1956, but the existence of two other abrupt changes in the period between these two changes makes the correlation doubtful. Thus, one is led to discount systematic errors in Washington or IPMS observations as a cause of the linear trends seen in the comparison of Washington latitude observations with derived latitude variations based on the IPMS pole positions.

If the observations of the International Polar Motion Service do represent the motion of the mean pole with some degree of precision, then the differences in latitude that are seen must be due to changes in the direction of the vertical in Washington. Paleomagnetic results for the rates of continental drift show typical speeds of 0.5 to $3.0 \mathrm{~cm} / \mathrm{yr}$ (Garland, 1968) corresponding to rates of variation in latitude of 0.00015 $\mathrm{yr}^{-1}$ to $0.0009 \mathrm{yr}^{-1}$. The rates in Table III are much greater than these rates predicted by the theory of continental drift. Unless the present day drift rates are much larger than those determined by paleomagnetism, it appears that continental drift is not the cause of the nonpolar variation.

Changes in the direction of the local vertical caused by a varying geopotential surface would then appear to be a reasonable cause of the difference between observed and derived Washington latitude variations. Geopotential surfaces change with the 


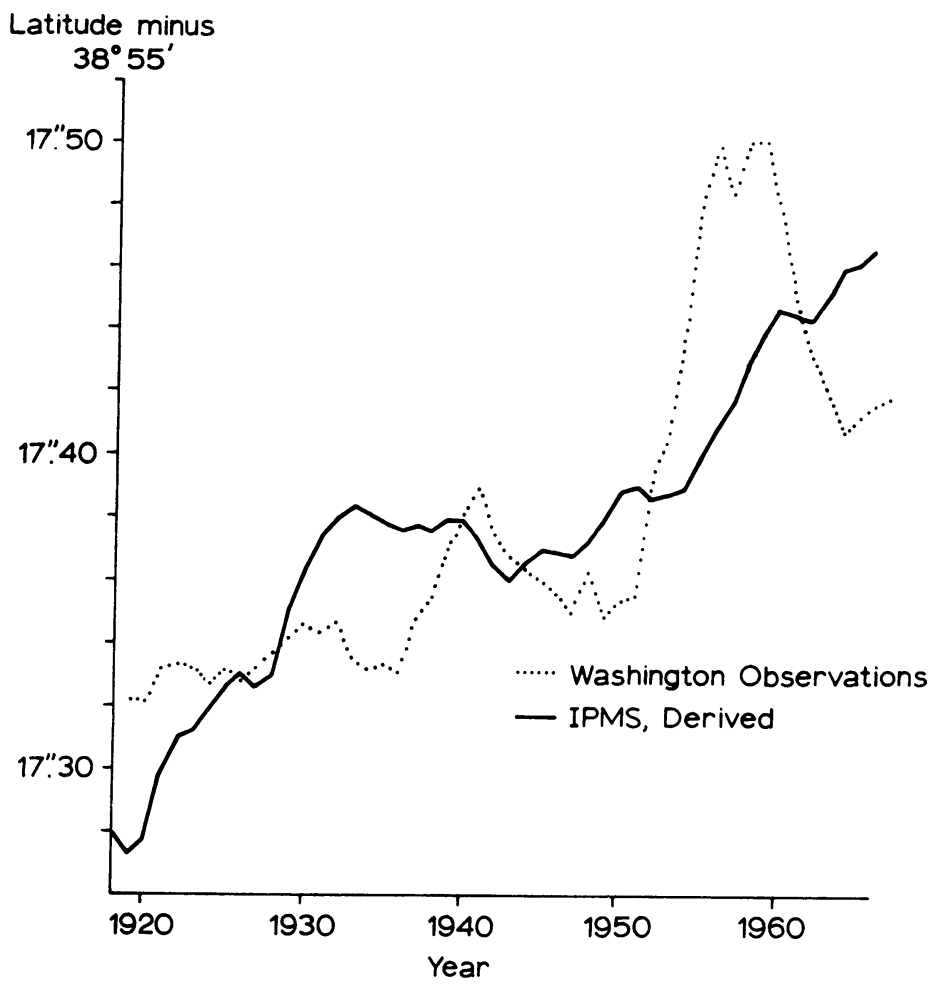

Fig. 5. Comparison of Washington observations with IPMS.

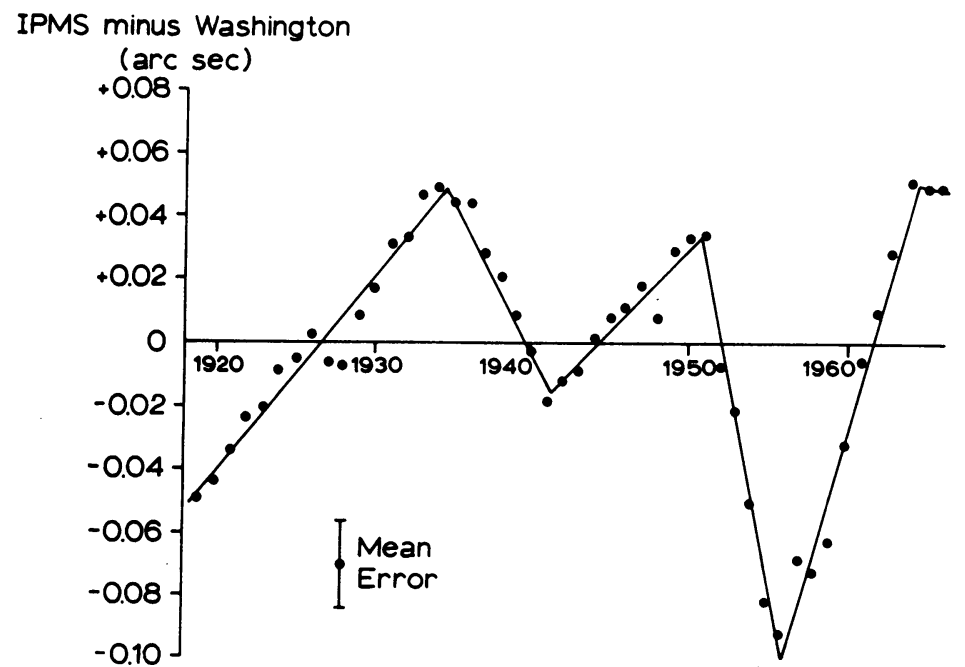

Fig. 6. Differences between observed Washington latitude and the latitude determined by the path of the rotational pole of the IPMS. 
TABLE IV

Major earthquakes that have occurred in the area shown in Figure 7. (Gutenberg and Richter, 1954; Sykes and Ewing, 1965; Rothe, 1969; United States Earthquakes, 1953-1967)

\begin{tabular}{|c|c|c|c|}
\hline Date & Position & & Magnitude \\
\hline Nov. 1923 & $19: 5 \mathrm{~N}$ & $73.5 \mathrm{~W}$ & 6.0 \\
\hline Feb. 1932 & $19: 5 \mathrm{~N}$ & $75: 5 \mathrm{~W}$ & 6.8 \\
\hline Jun. 1932 & $19: 5 \mathrm{~N}$ & $76: 5 \mathrm{~W}$ & 6.0 \\
\hline Apr. 1941 & $17: 8 \mathrm{~N}$ & $78.5 \mathrm{~W}$ & 7.1 \\
\hline Oct. 1952 & $18: 5 \mathrm{~N}$ & $73: 5 \mathrm{~W}$ & 5.9 \\
\hline Jul. 1956 & $20.0 \mathrm{~N}$ & $73: 0 \mathrm{~W}$ & 6.4 \\
\hline Mar. 1957 & $18: 4 \mathrm{~N}$ & $78.1 \mathrm{~W}$ & 6.5 \\
\hline Jul. 1962 & $18.9 \mathrm{~N}$ & $81.2 \mathrm{~W}$ & 6.0 \\
\hline
\end{tabular}

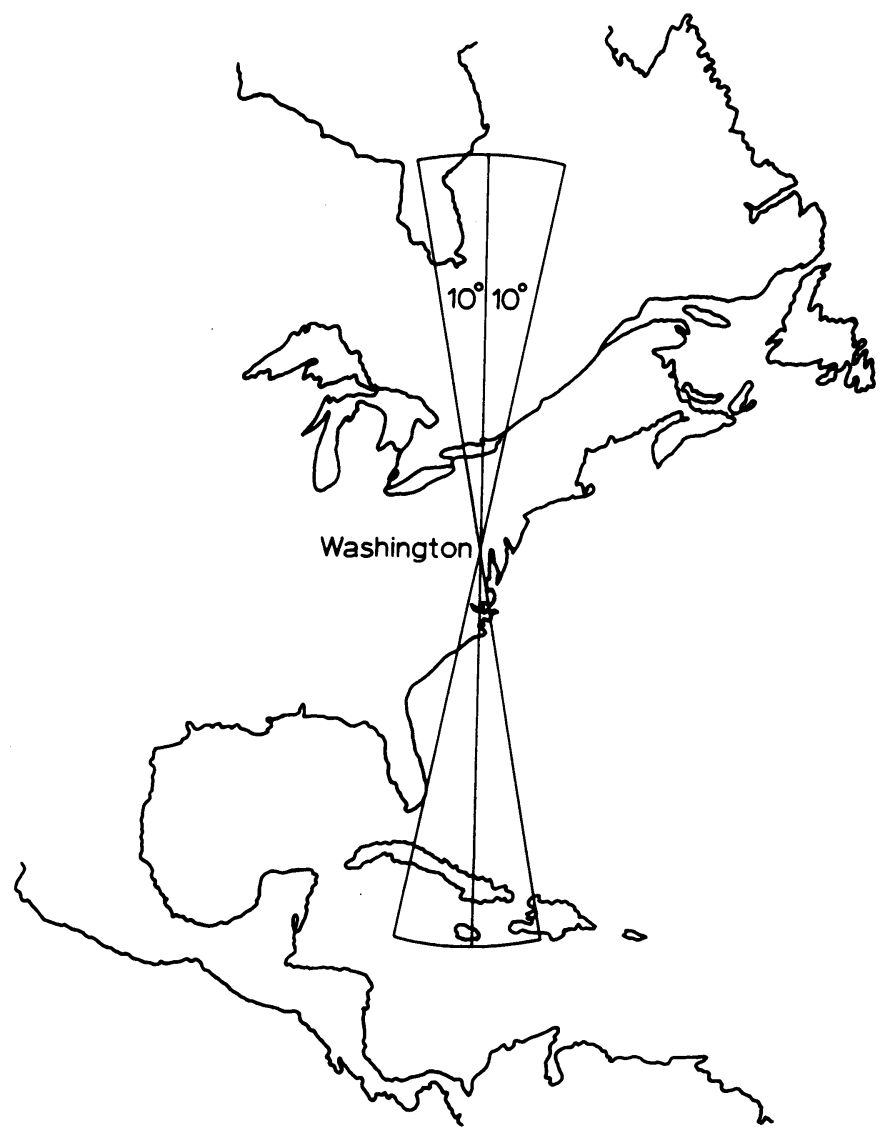

Fig. 7. Area in which seismic activity is assumed to have maximum effect on Washington latitude observations. 
redistribution of mass within the earth. Slow continuous changes in the direction of the vertical would then be reflected as a nonpolar latitude variation.

Table IV lists earthquakes with magnitudes greater than or equal to 5.9 on the Richter scale which have occurred in the area shown in Figure 7. This is the area within a distance of $3000 \mathrm{~km}$ bounded by lines making an angle of $\pm 10^{\circ}$ with the meridian of Washington. This area was chosen assuming that large mass movements there would have a maximum effect in tilting the vertical in the direction which would be measured as a change in latitude. It appears that seismic activity in this area in 1932, $1941,1952,1956,1957$, and 1962 may be correlated with the changes in the nonpolar variation of Washington latitude in the years 1934, 1941, 1951, 1956, and 1964. In addition the activity in late 1923 may be related to the distrubance shown in Figure 6 in the nonpolar variation seen in 1926.

The probability $(p)$ that any random year from the 48 year possible could fall within $\pm r$ years of a change in the nonpolar trend is $10 r / 48$. This is just the fraction of the entire time occupied by the $r$ year range of each of the observed five changes. If we randomly draw $N$ years the probability that $n$ or more will fall within the range of an abrupt change is given by the binomial probability

$$
P=\sum_{i=n}^{N}\left(\begin{array}{c}
N \\
i
\end{array}\right) p^{i}(1-p)^{N-i} .
$$

Table $\mathrm{V}$ shows the probability $(P)$ that such a correlation could be obtained on a random basis for values of $r$ equal to 1 and $2 \mathrm{yr}$.

\section{TABLE V}

Random probability of correlation of earthquakes with changes of slope in nonpolar Washington latitude variation

$\begin{array}{lllll}\begin{array}{l}\text { Range } \\ \text { (years) }\end{array} & \begin{array}{l}p \\ (10 r / 48)\end{array} & \begin{array}{l}N=\text { no. of } \\ \text { earthquakes }\end{array} & \begin{array}{l}n=\text { no. of } \\ \text { coincidences }\end{array}\end{array} \quad P=\sum_{i=n}^{N}\left(\begin{array}{c}N \\ i\end{array}\right) p^{i}(1-p)^{N-i}$

The low random probability indicates that seismic activity may be related to the changes in the rates of the nonpolar Washington latitude variation. The observed nonpolar variation may then be the manifestation of the changing geopotential surface brought on by slow movement of mass. The abrupt changes in direction of the nonpolar variation may then be the result of a sudden release of the accumulated strain energy through the associated seismic activity.

\section{Conclusions}

Observations with the Washington PZT since 1915 confirm the secular motion of the mean pole. The value of the linear rate of the secular motion obtained from these 
observations agrees with the value derived from the data of the International Polar Motion Service. True linearity of the motion is doubtful because of the sizeable systematic deviations. No evidence is found in the Washington data for the empirical 24 yr periodic libration proposed by Markowitz.

The differences between the observed latitude variation of Washington and the variation derived from the IPMS pole positions appears to vary piecewise linearly with time. The nonpolar variation may be the result of the changes in the direction of the vertical caused by the variation of the local geopotential surface. Abrupt changes in the slopes of the linear relations seem to be correlated with seismic activity in the nearest seismically active region in the Caribbean area. This leads to the conclusion that the associated seismic activity may be the release of the strain energy accumulated by the redistribution of mass.

This would indicate that caution should be used in the combination of latitude observations made at different stations, if they should be combined at all. Since precise astronomical positional work is done with respect to the local vertical, it would appear that variation in the direction of the local vertical as evidenced by nonpolar latitude variations must be considered in the determination of positions and proper motions. This would indicate that care should be exercised in comparing or combining fundamental observations made at locations which are widely separated either in time or geographically. It appears that geophysical effects on the direction of the vertical may not be negligible.

\section{References}

Garland, G. D.: 1968, in Wm-Markowitz and B. Guinot (eds.), 'Continental Drift, Secular Motion of the Pole and Rotation of the Earth', IAU Symp. 32, 19.

Gutenberg, B. and Richter, C. F.: 1954, Seismicity of the Earth and Associated Phenomena, Hafner Publishing Company, Inc., New York.

Hattori, T.: 1959, Publ. Int. Lat. Obs. Mizusawa 3, No. 1.

Markowitz, W.: 1960, Methods and Techniques in Geophysics, (ed. by Runcorn), Interscience Publishers Ltd., London.

McCarthy, D. D.: 1970, unpublished Master's Thesis, University of Virginia.

Munk, W. H. and McDonald, G. J. F.: 1960, The Rotation of the Earth, University Press, Cambridge.

Rothe, J. P.: 1969, The Seismicity of the Earth 1953-1965, UNESCO, Paris.

Sekiguchi, N.: 1954, Publ. Astron. Soc. Japan 5, 109.

Sekiguchi, N.: 1956, Publ. Astron. Soc. Japan 8, 13.

Sykes, L. R. and Ewing, M.: 1965, J. Geophys. Res. 70, 5065.

United States Earthquakes: 1953-1967, U.S. Government Printing Office, Washington.

Vicente, R. O. and Yumi, S.: 1969, Publ. Int. Lat. Obs. Mizusawa 7, No. 1.

\section{DISCUSSION}

Wm. Markowitz: (1) ILS did not derive a secular motion. (2) $24 \mathrm{yr}$ period was not predicted; the effect is empirical.

D. D. MCCarthy: For \#1 and \#2: The data of the IPMS (ILS) have been used by many authors to derive an apparent aperiodic motion of the pole. The interpretations of the observations differ among the authors. In the present paper the IPMS pole path was used to determine the secular motion of the pole as seen in the meridian of Washington. The $24 \mathrm{yr}$ libration, if it is real, is indeed an empirical effect. The Washington observations merely show no evidence of the $24 \mathrm{yr}$ libration. 
E. Proverbio: I think that the long term polar motion is very difficult to put in evidence for the meridian of Washington because for the period 1960-1970 the projection of the 24 period along the Washington meridian was very small.

D. D. McCarthy: The effect of the $24 \mathrm{yr}$ libration on the latitude of a station on the meridian of Washington is shown in the present paper. This curve is based on an analytical representation ofthe 24 yr libration given by Markowitz (1960) who used IPMS data from 1900 through 1959.2. 